\title{
ULTRAVIOLET SPECTRUM OF EXTRACT OF CENTELLA ASIATICA (VALLARAI) IN EDIBLE OIL AS SUPPLEMENT
}

\section{SOUNDRA PANDIAN G}

\author{
Department of Electronics and Communications, Madanapalle Institute of Technology and Science, Madanapalle, Chittoor, \\ Andhra Pradesh, India. Email: drpandiangs@mits.ac.in
}

Received: 07 November 2017, Revised and Accepted: 29 December 2017

\section{ABSTRACT}

Objective: The objective is to create 4 extracts of Centella Asiatica whole plants without using toxic chemicals based on an edible oil and water and to study the UV-vis absorption spectrum of the extracts.

Methods: An extract of the whole plant was taken in fresh form with green leaves, made in to a paste by using an electric grinder and the paste mixed with water was heated with coconut oil at temperatures below 100 degree $C$. The oil part and water part of the extracts were then taken and analysed in an UV-vis spectrometer. The experiment was repeated by using Centella Asiatica whole plants dried in sun for a day.

Results: The UV spectrum of the oil extract of undried Centella Asiatica whole plant showed absorption peaks at 413nm, 434 nm, 506nm, 537nm, $564 \mathrm{~nm}, 610 \mathrm{~nm}$ and $670 \mathrm{~nm}$. The oil extract of dried Centella Asiatica whole plant showed peaks at $413 \mathrm{~nm}$, and $670 \mathrm{~nm}$. The peaks between $434 \mathrm{~nm}$ and $670 \mathrm{~nm}$ in the oil extract were due to Chlorophyll. The strongest peak at $413 \mathrm{~nm}$ is the major signal of the extract and is thought to represent the flavonoid Rutin. The water part of the extract of the dried plants does not show any significant peak at $670 \mathrm{~nm}$ of the chlorophyll.

Conclusion: Four extracts of Centella Asiatica whole plant were studied. The oil part of the extracts showed a strong peak at 413 nm. The medicinal values of the 4 extracts of the plant need to be studied in detail.

Keywords: Centella asiatica, Edible oil extracts, UV-vis spectrum.

(C) 2018 The Authors. Published by Innovare Academic Sciences Pvt Ltd. This is an open access article under the CC BY license (http://creativecommons. org/licenses/by/4. 0/) DOI: http://dx.doi.org/10.22159/ajpcr.2018.v11i4.23519

There is an interest in the plant Centella asiatica for antiaging/memory enhancement in India. The author tried to make an extract of this plant. The whole plant was taken in fresh form with green leaves made into a paste using an electric grinder, and the paste was heated with an edible oil at temperatures below $100^{\circ} \mathrm{C}$. The extract was analyzed in an ultraviolet (UV) spectrometer. The absorption spectrum in the 400$800 \mathrm{~nm}$ region showed a strong presence of chlorophyll. To remove the chlorophyll from the extract, the author dried the $C$. asiatica whole plants in the sun for a day and repeated the experiment. The amount of chlorophyll got reduced in the final extract in the oil. Surprisingly, the water part of the extract did not show chlorophyll as most of the same got dissolved into the oil. The UV spectrum was clear and without noise in the 340-800 $\mathrm{nm}$ range and the oil extract of undried $C$. asiatica whole plant showed peaks at $413 \mathrm{~nm}, 434 \mathrm{~nm}, 506 \mathrm{~nm}, 537 \mathrm{~nm}, 564 \mathrm{~nm}$, $610 \mathrm{~nm}$, and $670 \mathrm{~nm}$. The fresh leaf of $C$. asiatica was reported [1] to have a peak at $299 \mathrm{~nm}$ also. The oil extract of dried $C$. asiatica whole plant showed peaks at $413 \mathrm{~nm}$ and $670 \mathrm{~nm}$. The peaks between $434 \mathrm{~nm}$ and $470 \mathrm{~nm}$ were due to chlorophyll. The strongest peak at $413 \mathrm{~nm}$ is thought to represent the flavonoid rutin present in the extract as the rutin was reported [2] to be having a UV spectrum peak around $410 \mathrm{~nm}$. The medicinal values of the oil extract and the water extract of the plant need to be studied in detail.

In India, the plant $C$. asiatica is known as Vallarai in Tamil and is being used as a medicinal plant, and it is believed that the plant improves the memory of old people. This plant contains [3-5] several compounds such as triterpenoids (asiaticoside, madecassoside, asiatic acid, madecassic acid, brahmoside, brahmic acid, brahminoside), glycosides, flavonoids (including rutin), alkaloids, steroids, volatile, and fatty oils. Traditionally, people used $C$. asiatica in the treatment of venous disorders, diuretic and blood cleanser. Other constituents reported [4] present in $C$. asiatica include flavonoids such as rutin, quercetin, and kaempferol and some phytosterols such as campesterol, sitosterol, and
stigmasterol.AsperWikipedia, beingasteroid, campesterol, $\beta$-sitosterol, or stigmasterol are a precursor of anabolic steroid boldenone. Boldenone undecylenate is commonly used in veterinary medicine to induce growth in cattle, but it is also one of the most commonly abused anabolic steroids in sports. Centella terpenoids, known as centelloids, include [5] asiaticoside, centelloside, madecassoside, brahmoside, brahminoside, thankunizide, sceffoleoside, centellose, and asiatic, brahmic, centellic, and madecassic acids; depending on the origin of the Centella plant material, these saponins can account for between $1 \%$ and $8 \%$ of the constituents [5].

Water extraction of asiatic acid [6] using $C$. asiatica nanopowders gave $50 \%$ higher extraction yield with $7.09 \mathrm{mg} / \mathrm{g}$ as compared to the micropowders of $C$. asiatica. Centella was found to contain significant amounts of madecassoside $(3.10 \pm 4.58 \mathrm{mg} / \mathrm{mL})$ and asiaticoside (1.97 \pm $2.65 \mathrm{mg} / \mathrm{mL}$ ) but was low in asiatic and madecassic acid [7]. In Marques et al. [8] reported that a methanol extract of $C$. asiatica given for 14 days significantly increased the antioxidant enzymes such as superoxide dismutase, catalase, and glutathione peroxidase in mice. Deka et al. [9] studied anticonvulsant effect of aqueous extract of $C$. asiatica in albino mice.

Flavonoids contents of $C$. asiatica are kaempferol, quercetin, rutin, apigenin, and naringin. Rutin, also called rutoside, quercetin-3-0rutinoside, and sophorin, is the glycoside combining the flavonol quercetin and the disaccharide rutinose. Gupta et al. [10] reported that rutin is an antioxidant and antioxidants are compounds that protect cells against the damaging effects of reactive oxygen species such as singlet oxygen, superoxide, peroxyl radicals, hydroxyl radicals, and peroxynitrite. Oxidative stress has been linked to cancer, aging, atherosclerosis, ischemic injury, inflammation, and neurodegenerative diseases. Antioxidant phytoconstituents of $C$. asiatica (in $\mu \mathrm{g} / \mathrm{mg}$ of extract) are reported in a catalog as [11] polyphenols $45.2 \mu \mathrm{g} / \mathrm{mg}$, flavonoids $14.6 \mu \mathrm{g} / \mathrm{mg}$, tannin $59.7 \mu \mathrm{g} / \mathrm{mg}$, and Vitamin C $9.5 \mu \mathrm{g} / \mathrm{mg}$. 


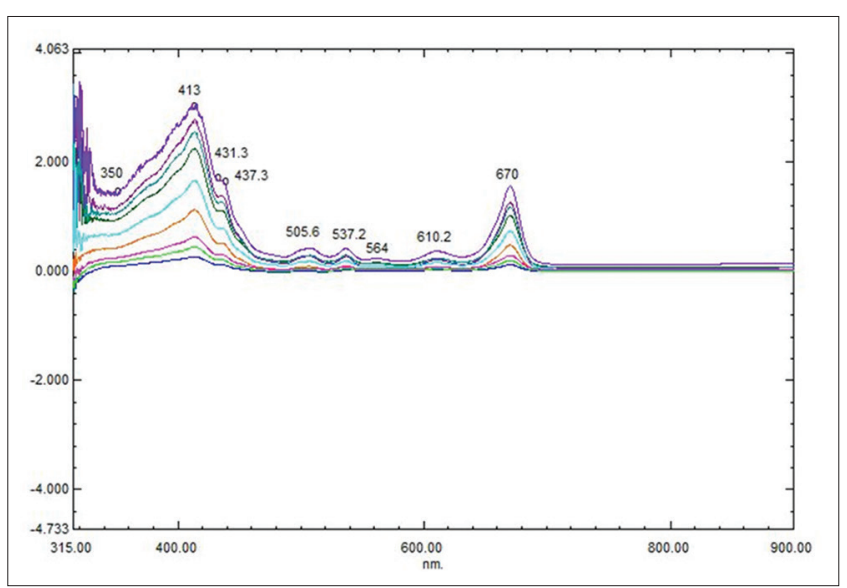

Fig. 1: Ultraviolet (UV)-visual spectrum of extract of fresh vallarai plant (Centella asiatica) in coconut oil for various concentrations of the extract sample used in the UV spectrometer

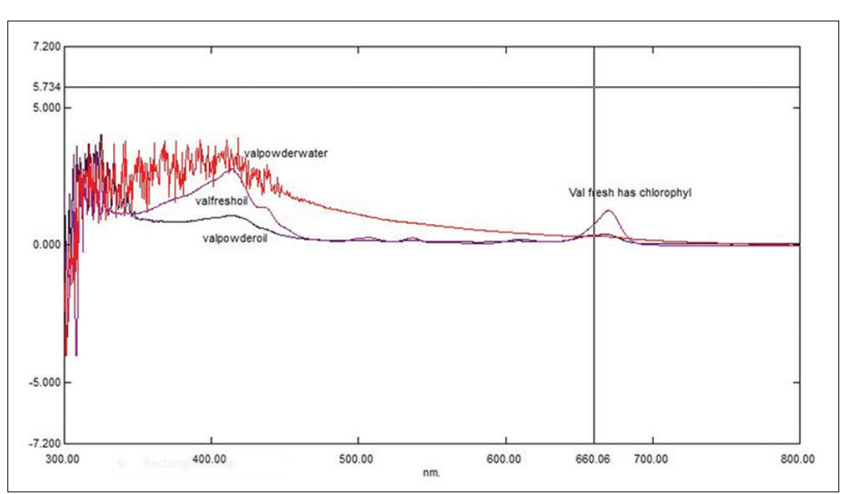

Fig. 2: Ultraviolet-visual spectrum of coconut oil extract of sundried vallarai plant (Centella asiatica) along with that of water part of the extract. The figure also shows the spectrum of extract of undried fresh plant for reference

Vasantharuba et al. [12] presented a review article on the functional properties of $C$. asiatica.

The author after making successful antiaging lycopene extracts on edible oils was wanting to study the possible use of $C$. asiatica plant for that purpose. Since the supplements are to be given to humans for a prolonged period, a toxic-free extract based on coconut oil was tried. The whole plant of $C$. asiatica was taken in fresh form with green leaves along with stem and roots made into a paste using a grinder, and the paste was heated with coconut oil at temperatures below $100^{\circ} \mathrm{C}$. The plant authentication was done personally by the author as the plants were taken from his own agricultural land and verified that the plant matched photographs and details mentioned on internet. Fig. 1 shows the UV-visual spectrum of the oil extract of the undried fresh whole plant for various concentrations.

The author identified in Fig. 1 the peak at $670 \mathrm{~nm}$ as well as the peaks down to $435 \mathrm{~nm}$ due to chlorophyll. The strong peak at $413 \mathrm{~nm}$ shows the main ingredient of the plant. A literature survey showed that the $413 \mathrm{~nm}$ peak may be due to the flavonoid rutin with reference to the spectrum shown in page 4 in Fig. 1 of [2] where rutin was shown as having a peak at $410 \mathrm{~nm}$.

The author was not happy with a strong presence of chlorophyll in the oil extract of the fresh whole plant of $C$. asiatica and tried to remove or reduce the chlorophyll content by drying the whole plant before oilbased extraction. The whole plant was dried in hot sun for a day and the leaves lost the bright green color and became brittle. Fig. 2 shows the results of the dried plant extract in coconut oil. To help in the extraction, some water was added when heated with the oil and the powder of the dried plant. The spectrum of the water part of the extract also is shown in Fig. 2 along with that of the extract in oil of the fresh plant for reference.

We see in Fig. 2 that the ratio of the signal at $670 \mathrm{~nm}$ and that at $413 \mathrm{~nm}$ has reduced in the oil part of the extract of the dried plant, and there is no peak signal at $670 \mathrm{~nm}$ in the water extract of the dried plant (measured with a concentrated sample to maximize the signal detection at $670 \mathrm{~nm}$ ). The author was satisfied with the reduction of the signal at $670 \mathrm{~nm}$ in the dried plant extract in oil.

There was too much noise in the measurement below $340 \mathrm{~nm}$, but we see that the dried part extract in oil showed a peak below $340 \mathrm{~nm}$ and it is thought that the actual peak might occur around $299 \mathrm{~nm}$ by comparing the spectrum of the green leaves of $C$. asiatica plant given in [1]. The water part of the extract of the dried plant had almost no chlorophyll (no peak at $670 \mathrm{~nm}$ ).

The medical use for the oil and water extracts will have to be studied, particularly for brain memory improvement in old age, antiaging, and other uses for cure of varicose veins and skin wrinkles/wound.

This paper presented a method of obtaining a non-toxic solvent method of extraction using the edible coconut oil of undried and dried C. asiatica (vallarai) plant and gave the UV spectrum for the extracts. We see that the oil extracts have a peak at $413 \mathrm{~nm}$ (due to flavonoids like rutin), around $300 \mathrm{~nm}$ (due to other constituents) and $670 \mathrm{~nm}$ due to chlorophyll.

\section{AUTHORS CONTRIBUTION}

Dr. G. Soundra Pandian contributed study conception and design, acquisition data, analysis and interpretation of data, drafting of manuscript, and critical revision.

\section{CONFLICTS OF INTEREST}

None.

\section{REFERENCES}

1. Vuong LD, Luan ND, Ngoc DD, Anh PT. Application of ultrasound for green synthesis of silver nanoparticles from fresh leaf extract of Centella asiatica and their antimicrobial activity. J Nano Energy Power Res 2014;3:1-5.

2. Fernandes AJ, Ferreira MR, Randau KP, De Souza TP, Soares LA. Total flavonoids content in the raw material and aqueous extractives from Bauhinia monandra Kurz (Caesalpiniaceae). Sci World J 2012;1-7.

3. Pramono HS, Nugroho AE. Triterpenoid-rich fraction of Centella asiatica leaves and in vivo antihypertensive activity. Int Food Res J 2014;21:149-54

4. Chong NJ, Aziz Z. A systematic review on the chemical constituents of Centella asiatica. Res J Pharm Biol Chem Sci 2011;2:445.

5. James J, Dubery I. Identification and quantification of triterpenoid centelloids in Centella asiatica (L.) Urban by densitometric TLC. J Planar Chromatogr 2011;24:82-7.

6. Borhan MZ, Ahmad R, Rusop M, Abdullah S. Green extraction: Enhanced extraction yield of Asiatic acid from Centella asiatica (L.) nanopowders. J Appl Chem 2013;2013:1-7.

7. Aslam H, Ali ST, Khan S, Khan BS, Siddiqui HE. Chemical constituents of Centella asiatica. J Asian Nat Prod Res 2007;9:407-14.

8. Marques NF, Stefanello ST, Froeder AL, Busanello A, Boligon AA, Athayde ML, et al. Centella asiatica and its fractions reduces lipid peroxidation induced by Quinolinic acid and sodium nitroprusside in rat brain regions. Neurochem Res 2015;40:1197-210.

9. Deka D, Chakravarty P, Purkayastha A. Evaluation of the anticonvulsant effect of aqueous extract of Centella asiatica in Alnino mice. Int J Pharm Pharm Sci 2017;9:312-4.

10. Gupta N, Chauhan RS, Pradhan JK. Chapter 5 on Rutin, Handbook of Medicinal Plants and their Bioactive Compounds. Waknaghat: Jaypee University of Information Technology; 2014.

11. Technical Data Sheet Centella asiatica Extract, RADIANT Inc. Catalog. Available from: http://www.eradiant.co.kr.

12. Vasantharuba S, Banumathi P, Premalatha MR, Arumugam T. Functional properties of Centella asiatica (L.): A review article. Int J Pharm Pharm Sci 2012;4:8-14. 